\title{
La movilización de los pensionistas en España como proceso de construcción y aprendizaje de una nueva identidad colectiva
}

The mobilization of pensioners in Spain as a process of
construction and learning of a new collective identity

Manuel JimÉneZ-SÁNCHeZ

Universidad Pablo de Olavide de Sevilla mjimsan@upo.es (ESPAÑA)

Raúl Álvarez PÉrez

Universidad Pablo de Olavide de Sevilla ralvper@upo.es (ESPAÑA)

Gomer Betancor Nuez

Universidad Nacional de Educación a Distancia

gbetancor@bec.uned.es (ESPAÑA)

Recibido: 24.102020

Aceptado: 23.07.2021

\section{RESUMEN}

El movimiento de los pensionistas en 2018 supuso la primera movilización multitudinaria basada en una identidad colectiva de personas mayores en España, y mostró una capacidad de contestación popular sin precedentes en el tema de las pensiones. Este trabajo indaga en el proceso de configuración de la identidad colectiva como estrategia analítica que permite entender la aparición y la naturaleza (exitosa) de la movilización. Siguiendo la conceptualización de Melucci, este proceso se analiza desde una doble perspectiva. Por un lado, como estrategia de actores colectivos que persiguen articular la contestación popular a la política de pensiones puestas en marcha durante la Gran Recesión. Aquí, el análisis se centra en identificar el proceso organizativo en el que se sientan las bases identitarias del movimiento, y que se extenderían con éxito en la fase posterior de contestación masiva. Por otro lado, se presta atención a la naturaleza 
de la identificación entre los propios pensionistas como resultado de procesos de aprendizaje durante sus experiencias de movilización. Para la primera perspectiva, el trabajo se basa en informaciones obtenidas en noticias de prensa sobre las actividades de protesta y en documentos producidos por las organizaciones del movimiento. La perspectiva individual de los participantes se fundamenta en el análisis de los discursos obtenidos en entrevistas personales focalizadas a participantes. Este doble enfoque, como estrategia organizativa intencionada y como proceso de aprendizaje durante la experiencia de la movilización, ofrece informaciones clave para comprender no solo el proceso, inédito en España, de construcción de una voz propia de los pensionistas sino también para indagar en los procesos de aprendizaje y cambio actitudinal que implican para los participantes corrientes. En un sentido más amplio, esta estrategia de análisis permite igualmente, por un lado, ubicar el proceso de movilización de los pensionistas en una trayectoria temporal más amplia de contestación popular y, en particular, vincularlo a los legados del ciclo de movilización que protagonizó el 15-M. Por otro lado, también permite destacar esos procesos de contestación como espacios de aprendizaje en los que se modelan actitudes, valores y demás elementos de la cultura de protesta.

\section{PALABRAS CLAVE}

Identidad colectiva, movimientos sociales, pensionistas, protestas de mayores, aprendizaje político.

\section{ABSTRACT}

The pensioners' movement in 2018 was the first mass mobilization based on a collective identity of older people in Spain, and showed an unprecedented capacity for popular contestation on the issue of pensions. This paper inquires into the process of collective identity configuration as an analytical strategy that allows us to understand the emergence and (successful) nature of the mobilisation. Following Melucci's conceptualization, this process is analysed from a double perspective. On the one hand, as a strategy of collective actors seeking to articulate popular contestation to the pension policies implemented during the Great Recession. Here, the analysis focuses on identifying the organizational process in which the identity bases of the movement are established and, which were successfully extended in the subsequent phase of mass protest. On the other hand, attention is paid to the nature of the collective identification among pensioners themselves as result of learning processes during their protest experiences. The analysis of the organizational configuration of the movement is based on information obtained from press reports on the protest activities and documents produced by the movement's organizations. The individual perspective of the participants relies on the analysis of the discourses obtained in focused inter- 
views with participants. This dual approach, as an intentional organizational strategy and as a learning process during the mobilization experience, provides key information to understand not only the process, unprecedented in Spain, of building a voice for pensioners, but also to investigate the learning processes and attitudinal change involved for ordinary participants. More broadly, it also allows, on the one hand, to place the process of mobilization of pensioners in a broader temporal trajectory of popular contestation and, in particular, to link it to the legacies of the cycle of mobilization in the wake of the 15-M movement. On the other hand, it also allows us to observe protest as learning spaces in which attitudes, values, and other elements of the culture of protest are modelled.

\section{KEY WORDS}

Collective identity, social movements, pensioners, older adults' protests, political learning.

\section{INTRODUCCIÓN ${ }^{1}$}

Las medidas de austeridad con las que se hizo frente a la Gran Recesión en España se tradujeron en un proceso de gradual deterioro de las pensiones públicas. En 2011, el gobierno socialista congeló su cuantía y endureció las condiciones de acceso, elevando progresivamente la edad legal de jubilación (de los 65 a los 67 años), y ampliando el periodo para el cálculo de su importe (de los 15 a los 25 últimos años). En 2013, una nueva reforma, por parte del gobierno conservador del PP, consolidó su progresiva depreciación al desvincular su revalorización del IPC previsto ${ }^{2}$. Desde entonces, hasta 2018, la revalorización anual se mantuvo en el $0,25 \%$.

Pese a su carácter regresivo, estas reformas apenas tuvieron contestación en la calle. Quizás porque su impacto en las condiciones de vida de los jubilados no se dejaron sentir en ese momento, quizás porque la protesta no se percibía como pertinente en un contexto en el que la situación de otros colectivos, como los desempleados, se podría entender como más acuciante ${ }^{3}$. Los colectivos de personas mayores que se movilizaron entonces, como los "Yayoflautas", lo hicieron

\footnotetext{
${ }^{1}$ Este trabajo es parte del proyecto de investigación, PROTEiCA: "Protesta, aprendizaje y cambio político" financiado por FEDER/ Ministerio de Ciencia, Innovación y UniversidadesAgencia Estatal de Investigación (Referencia CSO2017-84861-P).

2 Desde 1997, la revalorización se hacía, por ley, de acuerdo con el IPC. La reforma de 2013 introdujo el Índice de Revalorización de las Pensiones (IRP), que desvinculó el crecimiento de las pensiones del IPC, así como el factor de sostenibilidad, que vinculó la cuantía de la pensión a la esperanza de vida en cada momento.

${ }^{3}$ En 2014, con una tasa de desempleo del $26 \%$ de la población activa, hasta un $60 \%$ de las personas mayores declaraba ayudar económicamente a sus familiares, cuatro veces más que antes de la crisis. En 2016, todavía un 45\% seguía haciéndolo (UPD -Barómetro Mayores, 2018).
} 
en otras causas, contra los recortes, los desahucios o el deterioro del sistema democrático ${ }^{4}$. Sea como fuere, lo cierto es que, a diferencia de otros sectores, como la sanidad o la educación, que alimentaron el ciclo de movilización iniciado con el 15-M (Adell y Olayo 2014, Portos 2016), los pensionistas carecieron de una voz propia, al tiempo que los sindicatos no pudieron o no supieron contestar estas medidas.

Esta situación cambió radicalmente en 2018. Tras varios años seguidos de devaluación de las pensiones, la salida de la crisis coincide con un aumento de la tasa de pobreza entre los mayores ${ }^{5}$, así como del porcentaje de personas descontentas con la gestión de las pensiones ${ }^{6}$. En este contexto, el anuncio un año más de la subida del 0,25\% desencadenó sentimientos de agravio e indignación, espoleando, finalmente, una movilización de los pensionistas, sin precedentes en España, y comandada por colectivos de mayores.

La transcendencia política de estas movilizaciones resulta incuestionable. Ya en abril, en un intento infructuoso de desmovilizar a los pensionistas, el gobierno de Rajoy ajustó la subida de las pensiones al IPC previsto, pese a haberlo considerado previamente imposible. Su impacto también se reflejó en la opinión pública: en el barómetro de marzo de 2018 (CIS 2018), las pensiones destacan como el tercer problema de España mencionado con más frecuencia, triplicando los valores habituales en los años previos: hasta el 15,5\% (32\% entre el grupo de 65 años o más). Pero el movimiento no solo logró dar visibilidad al problema, también consiguió contestar el discurso dominante sobre la (in)viabilidad del sistema público de pensiones, haciendo visible un planteamiento alternativo posibilista.

Este trabajo indaga en el proceso de configuración de la identidad colectiva de los pensionistas como estrategia analítica que permite entender la aparición y la naturaleza (exitosa) del movimiento. Siguiendo la conceptualización de Melucci (1995), este proceso se aborda desde una doble perspectiva. Por un lado, como estrategia de actores colectivos que persiguen articular la contestación popular a la política de pensiones puestas en marcha durante la Gran Recesión. Aquí, el análisis se centra en identificar el proceso organizativo en el que se sientan las bases identitarias del movimiento, y que se extenderían con éxito en una fase posterior de contestación masiva. Por otro lado, se presta atención a los procesos de aprendizaje y la naturaleza de la identificación entre los propios pensionistas durante sus experiencias en las movilizaciones en 2018. Para la primera perspectiva, el trabajo se basa en el análisis de noticias publicadas en prensa y documentos producidos por las organizaciones del movimiento. La perspectiva individual de los participantes se fundamenta en el análisis de los discursos

${ }^{4}$ Los Yayoflautas significaron, no obstante, el primer caso de movilización alrededor de la identidad de los mayores en España (Schwarz 2019).

5 Según datos de la Encuesta de Condiciones de Vida del INE, desde 2014, los mayores de 65 años constituían el único grupo de edad en el que había aumentado de manera constante la tasa de pobreza, situándose en 2018 en 15,6\% (www.ine.es).

${ }^{6}$ De acuerdo con la serie del CIS, el porcentaje de insatisfechos (poco o nada satisfechos) con la gestión de las pensiones subió desde el 36\% en 2010 hasta el 57\% en 2017 (ww.cis.es). 
obtenidos en una serie de entrevistas focalizadas a participantes con distintos perfiles y grados de implicación en las movilizaciones. Esta doble aproximación, como estrategia organizativa intencionada (de arriba a abajo) y como proceso de aprendizaje (entre participantes) durante la experiencia de la movilización, ofrece información clave para comprender no solo el proceso, inédito en España, de construcción de una voz propia de los pensionistas sino también los procesos de aprendizaje y cambio actitudinal que implican para participantes no activistas.

\section{LA IDENTIDAD COLECTIVA COMO COMO ESTRATEGIA ORGANIZATIVA Y COMO APRENDIZAJE DURANTE LA PROTESTA}

La acción colectiva (y también la conectiva) implica cierto grado de identificación mutua (un "nosotros") y de sentido de agencia colectiva entre los participantes (Snow 2001). La identidad colectiva, así entendida, facilita los sentimientos de compromiso y solidaridad asociados a la participación. Se trata de un componente esencial de los movimientos sociales. Heberle, por ejemplo, hace siete décadas, consideraba que para la generación de un movimiento social "es necesaria la existencia de un sentimiento de identidad de grupo y solidaridad" (1951: 7). Por su parte, la influyente teoría de la acción colectiva destacó el papel de las organizaciones en la configuración de estos sentimientos como incentivos para la acción colectiva (Olson 1965). Si bien, fue a partir del giro culturalista en la década de 1980 cuando se presta más atención a la identidad colectiva en los procesos de contestación, orientando la observación hacia el origen, continuidad e impacto de la acción colectiva (Polletta y Jasper 2001). La identidad colectiva pasa a ser entendida como resultado del proceso de contestación más que una condición previa al mismo.

Desde esta perspectiva, la acción colectiva se conecta con la producción de significado, con los procesos por los que la gente da sentido al mundo y produce significados (Hunt y Benford 2004; Melucci 1989, 1995). Así, la identidad colectiva $^{7}$ no es considerada como reflejo de actitudes previas condicionadas en mayor o menor medida por las condiciones estructurales o contingentes del individuo, sino que se concibe como un proceso de aprendizaje que surge de (y fomenta) la interacción social (Fine 2018). En ese proceso productivo, los esfuerzos organizativos intencionados juegan un papel importante ${ }^{8}$ pero también resultan clave las dinámicas de interacción y aprendizaje individuales que tienen lugar durante la experiencia de la contestación.

El camino que lleva a una persona a identificarse como integrante de un colectivo activo, y al desarrollo de esos sentimientos aparejados de compromiso

7 Para una revisión del concepto de identidad colectiva en la literatura de los movimientos sociales, véanse, por ejemplo, Flesher Fominaya (2010) o Polletta y Jasper (2001).

${ }^{8}$ Gamson (1990) considera que cualquier movimiento que desee perdurar en el tiempo debe considerar la construcción de una identidad colectiva como una de sus tareas centrales. 
y solidaridad, se contextualiza en un proceso más amplio de cambio actitudinal vinculado a la experiencia de la protesta. Así, el cambio en las lealtades y los sentimientos de pertenencia entre participantes en las movilizaciones de los pensionistas estarían íntimamente vinculados a otros cambios individuales tales como los relativos a sus visiones del mundo (por ejemplo, a la comprensión del problema de las pensiones), los sentimientos de eficacia política, así como cambios en la confianza o lealtades hacia distintos actores políticos. Los eventos de protesta constituyen espacios de aprendizaje en los que se proporcionan modelos para el compromiso y se construyen visiones compartidas sobre las demandas,

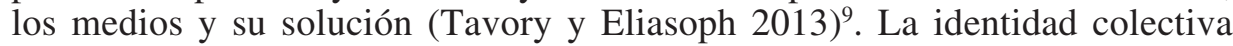
se construye, de esta manera, en el proceso de movilización, como momento de interacción social en el que se aprenden nuevas orientaciones simbólicas y significados que los integrantes reconocen, comparten y revisan continuamente (Simon y Klandermans 2001).

Para abordar el estudio empírico del proceso de construcción de una identidad colectiva nueva (y el surgimiento de un nuevo movimiento social), es posible distinguir analíticamente dos espacios de observación ${ }^{10}$. Por un lado, el proceso está conectado a las estrategias (intencionales) de organización, espacios donde se definen determinadas visiones del mundo y orientaciones hacia la acción (marcos movilizadores) y se intentan proyectar hacia potenciales seguidores, el público en general, etc. Por otro lado, la identidad colectiva es experimentada o aprendida, como hemos mencionado, durante la acción, en un proceso de interacción (comunicativa).

La naturaleza de ese proceso de configuración de la identidad colectiva define la capacidad de un colectivo para llevar a cabo una acción autónoma, como sujeto unificado y delimitado, y consciente (con percepción de control) de sus acciones. Esta capacidad se expresaría en la configuración de un movimiento con una voz propia, diferenciada de otros actores preexistentes. El reflejo de esta nueva identidad se observaría no solo en la auto-identificación entre participantes, la existencia de un "nosotros" más o menos amplio, sino también en el reconocimiento (positivo o negativo) por parte de otros actores, ya sean simpatizantes, aliados, antagonistas o meros observadores. Igualmente se reflejaría en su reconocimiento como interlocutores válidos por parte de las autoridades destinatarias de sus demandas.

Desde esta perspectiva, el proceso de identificación colectiva de los pensionistas puede considerarse como expresión del proceso de extensión y consolidación de un tejido organizativo propio del movimiento, en el que asociaciones de mayores preexistentes, más convencionales, y los sindicatos y sus secciones de jubilados, juegan un papel secundario. Los primeros esfuerzos organizativos y de

${ }^{9}$ Conceptos como el de liberación cognitiva (McAdam 1982: 48) o de liberación emocional (Jasper 1998) recogen estos procesos de cambio actitudinal vinculados a la acción colectiva en movimientos sociales.

${ }^{10}$ Estos dos espacios se corresponden con la distinción entre las facetas interna y externa de la identidad colectiva de Melucci (1995). 
construcción identitaria se pueden situar en las distintas iniciativas, de ámbito local, que surgen durante el ciclo de movilización de la Gran Recesión, en la estela del 15-M, como respuestas a las reformas de las pensiones mencionadas. Esas iniciativas cristalizan posteriormente en diversas estructuras organizativas de ámbito supralocal, que propiciarán, reforzándose al mismo tiempo, un proceso de extensión y generalización del conflicto que se acelerará a partir de 2018. El análisis de la percepción del movimiento por parte de los participantes permite explorar el proceso de construcción de la identidad colectiva del movimiento, identificando los elementos clave alrededor de los que se construye (o se aprende) la identidad colectiva durante la experiencia de la protesta y su conexión con las estrategias organizativas de los prootores.

\section{EVIDENCIAS Y ESTRATEGIA DE ANÁLISIS}

Las movilizaciones de los pensionistas, por su novedad y extensión, ofrecen un caso ideal para explorar el proceso ex novo de configuración de la identidad colectiva de un movimiento social. Para tal fin, se implementó una doble estrategia de análisis. Por un lado, a partir de noticias sobre las actividades de protesta y documentos producidos por las organizaciones y observadores informados se identifica el origen organizativo del movimiento y se traza su evolución hasta finales de 2018. En segundo lugar, a partir de entrevistas focalizadas (Valles 2002: 19 y ss.) a una muestra variada de participantes se indaga en la naturaleza de la identificación con el movimiento. Esta indagación permite comprobar la existencia de sentimientos de pertenencia e identificar los componentes discursivos sobre la que se sostiene y, al mismo tiempo, conectarlos con los esfuerzos organizativos para favorecer la acción colectiva por parte de los promotores de las protestas.

El análisis de actividades de protesta relacionadas con las pensiones y la evolución organizativa se realizó a partir de búsquedas acotadas de noticias en el buscador de Google durante el periodo 2011-2018 y de informaciones disponibles en los sitios webs de los colectivos de pensionistas. El trabajo se centró en identificar los eventos organizativos y de protesta más relevantes (de ámbito estatal) vinculados a la configuración organizativa del movimiento, y su extensión durante el proceso de generalización de las protestas en 2018. Este análisis ofrece una imagen (parcial) de la génesis organizativa del movimiento y permite identificar los rasgos que sientan las bases de su identidad colectiva.

Las entrevistas focalizadas ofrecen información valiosa para reconstruir ese proceso (exitoso) de movilización desde la perspectiva individual de participantes "corrientes". Para la selección de las personas entrevistadas, se siguió un muestreo intencionado para garantizar diversidad de perfiles (Patton 1990). Finalmente se realizaron 24 entrevistas a participantes con distinto nivel de implicación en las movilizaciones, desde asistentes esporádicos a las manifestaciones hasta implicaciones más intensas en grupos de ámbito local. Se buscaron perfiles que no tuvieran un registro previo de activismo intenso, sin vínculos previos 
con los promotores, de manera que estas protestas supusieran una experiencia novedosa y, por tanto, con mayor potencial de transformación en sus actitudes e identificaciones. Las entrevistas se realizaron en las zonas metropolitanas de Sevilla (4), Madrid (4) y Bilbao (16). Aunque en los tres contextos las movilizaciones de la primera mitad del año tuvieron una gran repercusión, Bilbao (y, en general, Vizcaya) se configuró como el espacio de contestación más intenso ${ }^{11}$. Se realizaron de manera presencial entre noviembre de 2018 y enero de 2019; se sitúan, por tanto, al final del primer año de intensa movilización.

La Tabla 1 sitúa a las personas entrevistadas en función, tanto del nivel de implicación en el movimiento como de experiencia previa de participación en protestas. Los códigos de las entrevistas indican el territorio de residencia, el sexo (7 mujeres y 17 hombres), la edad (entre 60 y 88 años) y el nivel de estudios (ultimo dígito del código, para una escala de 1 a 3 ). Como puede observarse, las personas entrevistadas presentan grados diversos de implicación en el movimiento y de experiencia contestataria previa. Por ejemplo, 11 de las 24 entrevistas corresponden a personas con un nivel alto de implicación en las movilizaciones, participando regularmente en acciones de protesta y, con frecuencia, en asambleas y actividades organizativas de los grupos locales. En bastantes casos, la experiencia contestataria anterior a estas movilizaciones se reducía a la asistencia puntual a manifestaciones o la participación en algún conflicto laboral.

${ }^{11}$ El mayor número de entrevistas en Bilbao responde precisamente a esta mayor intensidad de la movilización, que nos permitió encontrar perfiles de participantes con niveles elevados de implicación en las movilizaciones sin un registro previo de participación regular en manifestaciones, logrando diversidad en los perfiles y saturación discursiva dentro de ellos (Valles 2002) Un número importante de entrevistas en Bilbao corresponden a participantes en la plataforma de Baracaldo, una de las más activas. Los autores agradecen la colaboración de todas las personas entrevistadas, así como de las plataformas y colectivos que colaboraron en la captación y organización de las entrevistas. 
Tabla 1. Perfil de los entrevistados. Posición en función de la experiencia previa y grado de implicación en las movilizaciones

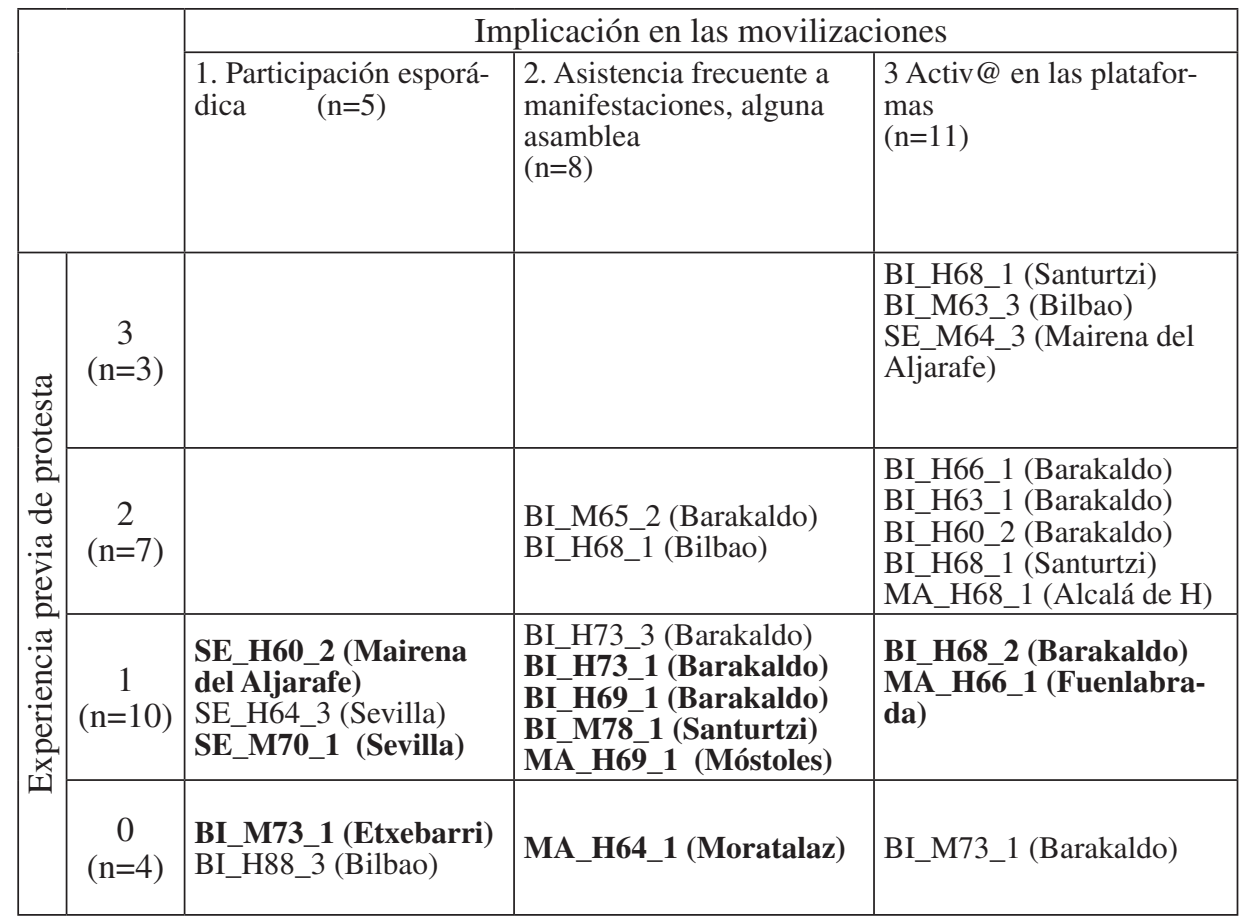

Fuente: Elaboración propia.

Interpretación del código: Las dos primeras letras indican la zona (BI, Bilbao, MA, Madrid, SE, Sevilla); la primera letra el sexo; los dos dígitos siguientes la edad y, la última cifra, el nivel de estudios (1, hasta primaria; 2 secundaria y 3 universitarios). Los códigos resaltados corresponden a personas que al menos inicialmente se movilizan por considerarse afectados materiales (versus una motivación universal o "por otros" para movilizarse).

Una reclamación central, y desencadenante de las movilizaciones, fue de tipo económico: la revalorización de las pensiones. En la tabla se han resaltado en rojo aquellas entrevistas en las que aparecen estas motivaciones materiales (particulares) para salir a la calle, al menos en un primer momento. Como puede apreciarse, la condición subjetiva de afectado material es más frecuente entre las personas con menos experiencia previa de protesta. En el resto de las entrevistas, se suele encontrar la idea de movilizarse "por otros" como motivación fundamental para salir a la calle (por los que no tienen para llegar a finales de mes, por los jóvenes, por el carácter público del sistema de pensiones, etc.).

Las personas entrevistadas fueron captadas a partir invitaciones difundidas en redes sociales en las que se les solicitaban algunos datos sociodemográficos y relativos a su experiencia de participación en protestas. La estrategia inicial de captación directa se completó con contactos a distintos colectivos locales en los 
territorios seleccionados solicitando la difusión de las invitaciones entre sus seguidores. Las expresiones de interés obtenidas, unas 270 en total, se recogieron mediante un formulario online y, en algunos casos, completados por teléfono. A partir de los datos recogidos, se procedió a concretar las entrevistas mediante llamadas telefónicas, entre aquellos casos que a priori mejor se ajustaban a los perfiles buscados ${ }^{12}$.

Las entrevistas tuvieron una duración media de 90 minutos y fueron transcritas para su análisis. El guion de las entrevistas estaba orientado a la reconstrucción de las experiencias personales de participación en las movilizaciones, vinculándolas a potenciales cambios cognitivos, actitudinales y emocionales. Para aumentar la validez de nuestras evidencias, las entrevistas siguieron un enfoque no dirigido, combinando preguntas no-estructuradas y semi-estructuradas. En este sentido, al hilo de la conversación, cuando no surgía de manera espontánea, se preguntaba por la opinión sobre los colectivos de pensionistas promotores de las protestas y por los sindicatos (que también promovían y estaban presentes en las movilizaciones).

Para el análisis empírico se adoptó una estrategia inductiva basada en un proceso de codificación abierta (Strauss y Corbin, 1990) apoyado en el software Atlas.ti. Este proceso se hizo en dos fases mediante una codificación intersubjetiva con la implicación de dos codificadores. En la primera fase, se consideraron un número reducido de transcripciones, donde los codificadores identificaron citas con referencias al movimiento o a los sindicatos, y establecieron una serie preliminar de códigos que clasificaban componentes discursivos de sentido afín. En una segunda fase se trabajó con la totalidad de las transcripciones, en la que mediante la comparación constante se revisaron las definiciones de los códigos y su asignación a las citas. Además de la frecuencia de estos componentes discursivos, en el análisis se observan sus co-ocurrencias en los relatos de las personas entrevistadas, así como su asociación con sus distintos perfiles.

\section{EL INICIO DE LAS MOVILIZACIONES DE PENSIONISTAS EN ESPAÑA EN 2018}

"Yo empecé en la primera vez, el 15 de enero (...) nos pusimos en [nombre de la localidad], yo no fui a Bilbao, en frente del Ayuntamiento, aproximadamente, ¿qué estaríamos? ¿15, 20 personas? No habría más. De manos cruzadas, simplemente mirando para el Ayuntamiento, sin más. Ahí nadie dijo: "Ni esta boca es mía". Nadie habló. Estuvimos media hora allí paraditos, como chicos buenos, y ya está. Luego ya nos juntamos conocidos que estamos dentro del pueblo, y dijimos: "Oye, alguien tiene que empezar a hablar (...) "Alguien tiene que dar información”. Entonces (...) decidimos coger un

${ }^{12}$ Las entrevistas se realizaron de acuerdo con un protocolo aprobado por el Comité Ético de Investigación de la Junta de Andalucía (código 1581-N-18), y autorizado por el Vicerrectorado de Investigación de la Universidad Pablo de Olavide. Antes de las entrevistas, los participantes recibieron una hoja informativa y firmaron un documento de consentimiento. 
megáfono, y a la semana siguiente empezar a informar. Y así es como empezó todo. A medida que íbamos informando, aquello se iba llenando de gente..." (BI_H68_1)

El movimiento de pensionistas se dio a conocer de manera amplia el día 22 de febrero de 2018, cuando convocados por la Coordinadora Estatal por la Defensa del Sistema Público de Pensiones (COESPE), miles de personas, en su mayoría pensionistas, se movilizaron en numerosas de ciudades y pueblos, para exigir unas pensiones dignas y una revalorización conforme al IPC ${ }^{13}$. En las televisiones y periódicos, se repitieron las imágenes de pensionistas enfadados/as, rasgando la carta de la Ministra de Trabajo, Fátima Báñez (PP) que habían recibido a finales de año y en la que se anunciaba, por quinto año seguido, la subida del $0,25 \%$ de las pensiones, lejos del IPC previsto $(1,65 \%)$.

No obstante, la espiral de movilización ciudadana, que emerge a la luz pública en febrero, se había iniciado en las semanas previas. Como recoge la cita anterior (y en otras entrevistas), desde el 15 de enero se habían venido celebrando concentraciones los lunes en las plazas de los ayuntamientos de distintas ciudades del territorio español. Estas movilizaciones resultaron especialmente multitudinarias en Bilbao y distintas localidades de Vizcaya (Alejos, 2018), apuntado la fuerza que alcanzará el movimiento en esta zona. Pero la dinámica de movilización, tanto en Vizcaya como en otros lugares, fue parecida: difusión, a través de wasaps, de una convocatoria anónima de concentración ${ }^{14}$, y configuración de grupos locales, con la organización de esa manifestación del 22 de febrero como primer objetivo de su actuación.

El anuncio de la revalorización del 0,25\% también había llevado a los sindicatos mayoritarios a convocar movilizaciones. El jueves 18 de enero, por ejemplo, unas 500 personas se concentraron en las puertas del Congreso en Madrid para exigir una subida de acuerdo con el incremento del coste de la vida ${ }^{15}$. Previamente, a principios de octubre del 2017, CCOO y UGT habían organizado las marchas por la "dignidad de las pensiones", en un momento en el que estaban solicitando la derogación de la reforma de 2013. Las marchas, que culminaron en Madrid el 9 de octubre con una manifestación de unos 1000 participantes, estuvieron protagonizadas fundamentalmente por antiguos sindicalistas e integrantes de las federaciones de personas jubiladas de los sindicatos ${ }^{16}$. A partir de enero de 2018, por el contrario, las movilizaciones desbordan el ámbito de la militancia sindical y pasan a estar protagonizadas por una muestra más amplia de los más de 9 millones de pensionistas.

${ }^{13}$ La participación resultó especialmente masiva en algunas capitales de provincia como Bilbao, Sevilla o Valencia, según recoge la prensa ese mismo día.

${ }_{14}$ Según varias de nuestras entrevistas el mensaje era algo parecido a "El día 15 de enero a las 12 en el Ayuntamiento para protestar por el 0,25".

15 Véase, por ejemplo: https://www.publico.es/economia/centenares-jubilados-claman-puertas-del-congreso-pensiones-dignas.html.

16 Véase, por ejemplo: https://elpais.com/economia/2017/10/09/actualidad/1507547602 167880.htm 
Como se refleja en la línea del tiempo en la figura 1, a lo largo de 2018 se sucedieron las concentraciones en las plazas de los ayuntamientos. Movilizaciones que se fueron coordinando en convocatorias mensuales de ámbito estatal. Algunas de estas jornadas son impulsadas por los sindicatos (señaladas a una altura media en la línea del tiempo), pero a medida que avanza el año, las organizaciones del movimiento y, concretamente la COESPE a nivel estatal, adquieren el papel protagónico en la estrategia de movilización (señaladas arriba, en la parte superior de la línea del tiempo).

De esta manera, el 17 de marzo se volvieron a celebrar movilizaciones masivas en muchos municipios. Pocas semanas más tarde, durante la tramitación de los presupuestos generales, el gobierno del PP aceptó incluir una revaloración conforme al IPC $(1,6 \%)^{17}$. Sin embargo, la concesión de esta medida no detuvo las movilizaciones. La moción de censura y el cambio de gobierno en los siguientes meses, tampoco tuvo efectos desmovilizadores. El 19 de junio, bajo el lema "Gobierne quien gobierne, las pensiones se defienden", miles de pensionistas volvieron a reclamar pensiones dignas y el resto del contenido de la "tabla reivindicativa" del movimiento. El año terminó con celebración de una jornada con manifestaciones en más de 70 ciudades del todo el país ${ }^{18}$.

${ }^{17}$ Rajoy venía advirtiendo del peligro de "politizar" una cuestión tan sensible para los objetivos de déficit presupuestario. Véase, por ejemplo, http://www.rtve.es/noticias/20180223/rajoy-rechaza-subida-pensiones-tengo-mirar-medio-largo-plazo/1683672.shtml).

${ }^{18}$ Véase, por ejemplo, https://elpais.com/politica/2018/12/15/actualidad/1544903184_838127. html

EMPIRIA. Revista de Metodología de Ciencias Sociales. N. 52 septiembre-diciembre, 2021, pp. 97-124.

ISSN: 1139-5737, DOI/ empiria.52.2021.31366 


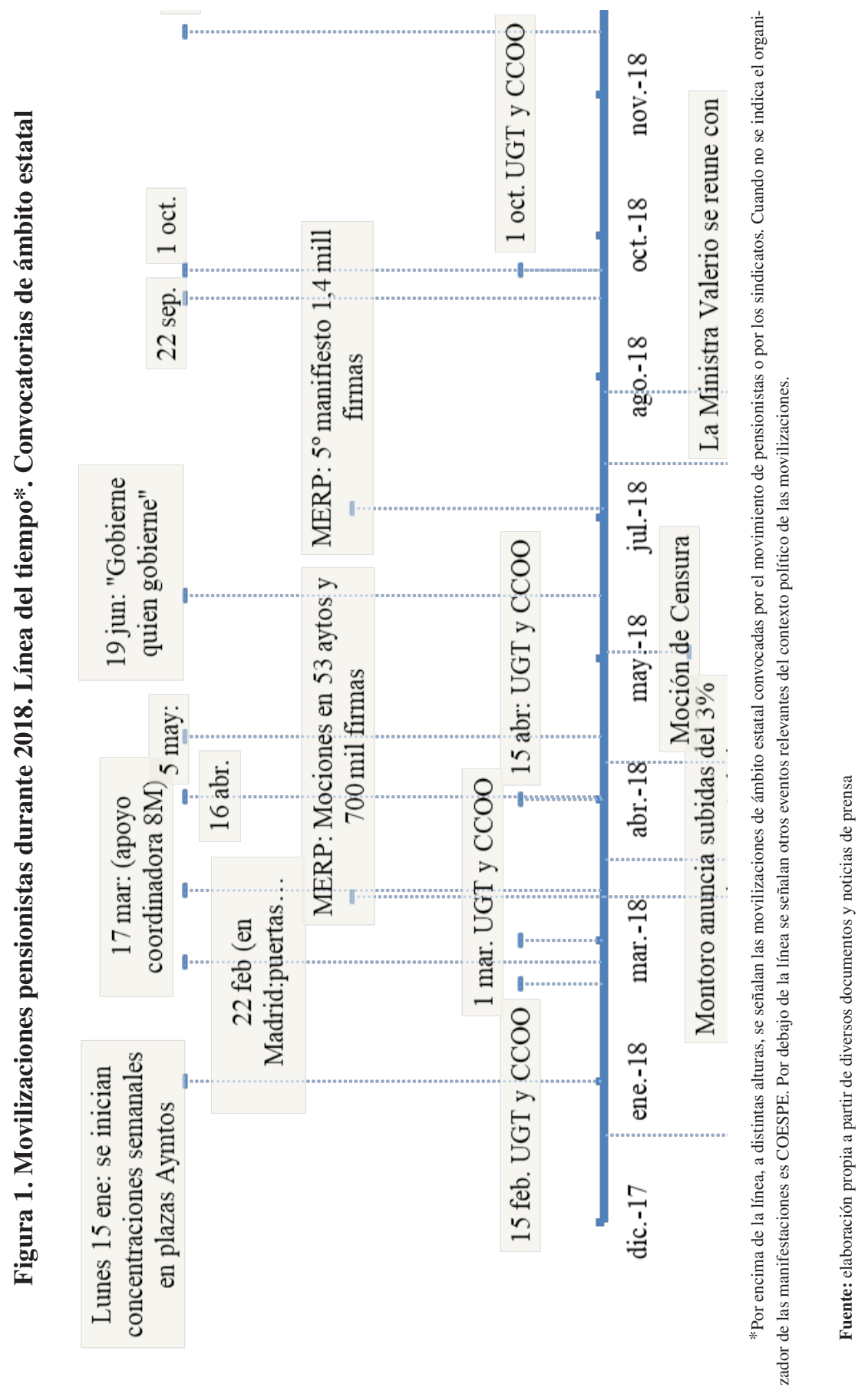

EMPIRIA. Revista de Metodología de Ciencias Sociales. N.o 52 septiembre-diciembre, 2021, pp. 97-124. ISSN: 1139-5737, DOI/ empiria.52.2021.31366 
Como se refleja en la figura 1, la evolución de la contestación en la calle sugiere que las organizaciones del movimiento, ejemplificadas aquí en la COESPE, no solo fueron capaces de movilizar masivamente a los pensionistas (a diferencia de los sindicatos mayoritarios) sino que consiguieron mantener viva esa movilización en el tiempo, superando las potenciales dinámicas de instrumentalización partidista, las dificultades de coordinación que conllevan las diferencias territoriales o los cambios en la configuración política de poder ${ }^{19}$. La continuidad de las movilizaciones en otoño, tras el cambio de gobierno y aprobada la revaloración conforme al IPC, son indicativas de la capacidad de acción autónoma del movimiento. Su rápido reconocimiento por parte del nuevo Ejecutivo socialista como interlocutor válido, al margen de los sindicatos, confirman su acceso al proceso de toma de decisiones con voz propia ${ }^{20}$. En pocos meses se había configurado un nuevo actor colectivo, protagonizado por los propios pensionistas con una capacidad de movilización sin precedentes en España.

\section{EL PROCESO DE CONFIGURACIÓN ORGANIZATIVA DEL MOVIMIENTO: LA IDENTIDAD COLECTIVA COMO ESTRATEGIA "DESDE ARRIBA"}

El proceso de configuración de un movimiento social, de su identidad colectiva como expresión empírica del mismo, puede observarse a partir de los esfuerzos organizativos para definir y promover la acción colectiva en unos términos determinados (Melucci 1995). Un objetivo esencial de los promotores de un proceso de contestación reside en establecer y mantener una identidad colectiva propia, cohesiva y facilitadora de la incorporación de participantes y de su compromiso en el tiempo.

Los antecedentes organizativos de las movilizaciones de pensionistas se pueden encontrar en los legados del 15-M y las movilizaciones anti-austeridad durante la crisis. La reforma de las pensiones de 2013, provocó los primeros pasos de articulación organizativa del colectivo. En aquel año, a instancias de estos colectivos y de emprendedores de la protesta, se celebran reuniones de ciudadanos y ciudadanas, muchos jubilados/as, muchos/as activos/as también

${ }^{19}$ Esto no quiere decir que no existan tensiones dentro del movimiento de pensionistas. El caso más evidente puede ser el movimiento en Euskadi, donde el nacionalismo y demandas específicas como la transferencia de las competencias, complejizan la unidad de acción (Véanse, por ejemplo, Alejos (2019, enero 27) o Azumedi (2019, diciembre 6).

${ }^{20}$ A finales de julio, la Ministra de Trabajo, Valerio, se reúne con COESPE y acuerdan calendario de reuniones e intervenir en reuniones Pacto Toledo (véase, por ejemplo https://www. facebook.com/COESPE/posts/486259838488365). Sin embargo, esa interlocución directa terminar de cristalizar. Las negociaciones en el Pacto de Toledo se rompieron sin acuerdo a principios de 2019. Cuando se retoman, el movimiento quedó excluido de las consultas, y el acuerdo alcanzado a finales de 2020 en forma de recomendaciones no refleja de manera satisfactoria las reivindicaciones del movimiento (véase por ejemplo, el comunicado de la COESPE https://www.65ymas. com/opinion/unidad-coespe-comunicado-pacto-toledo_20812_102.html). 
en otras movilizaciones anti-austeridad, como los "Yayoflautas" o los "Afectados por las Preferentes". Estas iniciativas surgen primero en el ámbito local en distintos territorios como Cataluña, Canarias y Andalucía ${ }^{21}$, y van dando lugar a Plataformas y Mareas Pensionistas en defensa de las pensiones ${ }^{22}$. En la línea del tiempo que hemos elaborado (figura 2) para trazar este proceso, se recogen algunos de estos hitos organizativos, señalando también, en parte inferior de la línea temporal, algunos eventos relevantes del contexto político y las primeras movilizaciones.

Los contactos entre esos grupos en distintas localidades propician la acción conjunta en un proceso de coordinación, de abajo a arriba, que más tarde, en la fase de expansión favorecerá y determinará la naturaleza de la movilización. La descentralización (y autonomía local), junto a otros rasgos, como la transversalidad y el asamblearismo, son frecuentes en los movimientos sociales progresistas en España (Jiménez y Calle 2007), que se expresan y refuerzan con la experiencia del 15-M (Flesher-Fominaya 2015) y permiten conectar al movimiento de los pensionistas las movilizaciones motivadas por la crisis y, de manera más amplia, con esa tradición contestataria en España ${ }^{23}$.

En este sentido, en 2015, Marea Pensionista impulsó la coordinación de los diversos grupos locales que condujo en septiembre de 2016, a la celebración de un primer encuentro estatal (al que también acuden numerosas organizaciones sociales y colectivos sindicales) y a la creación de la COESPE ${ }^{24}$. Aunque su primera convocatoria de manifestación en diciembre de 2016 pasó desapercibida, el trabajo de articulación de contactos y redes durante el año siguiente daría su fruto en las movilizaciones populares que se iniciaron el 15 de enero de 2018.

${ }^{21}$ Véase entrevista a Victoria Portas en https://ametzagaina.org/2018/08/24/victoria-portas-nos-habla-de-la-coordinadora-estatal-por-la-defensa-del-sistiema-publico-de-pensiones/

${ }_{22}$ Surgen igualmente acciones colectivas de ámbito supralocal centradas en campañas concretas, como la Mesa Estatal por el Blindaje de las Pensiones (MERP) en 2013, que promueve una reforma constitucional para defender las pensiones públicas, o ASJUBI40 en 2015, que defiende que no se penalice la jubilación anticipada a partir de los 40 años de cotización. En 2017, la campaña de recogida de firmas de la MERP había alcanzado casi 1,5 millones de adhesiones. (www. merp.es).

${ }^{23}$ En sus comentarios sobre el movimiento de pensionistas en Euskadi, Alejos (2018) identifica estos rasgos de descentralización, asamblearismo y transversalidad.

${ }^{24}$ Las pensiones dignas configuran un tema central del encuentro estatal de Yayoflautas ese mismo año, en Valencia (véase, por ejemplo, http://www.cadtm.org/Estos-ladrones-nos-roban-las) 
몽
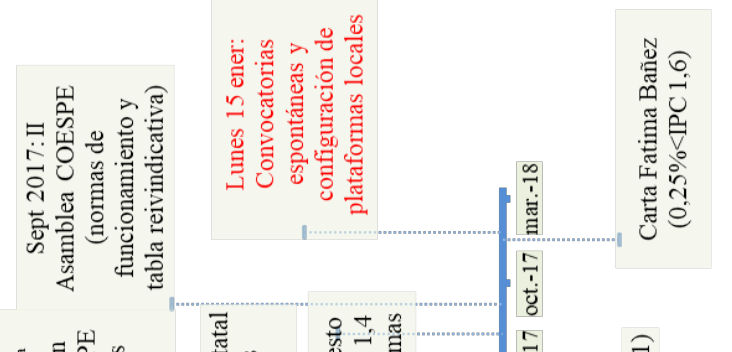

先
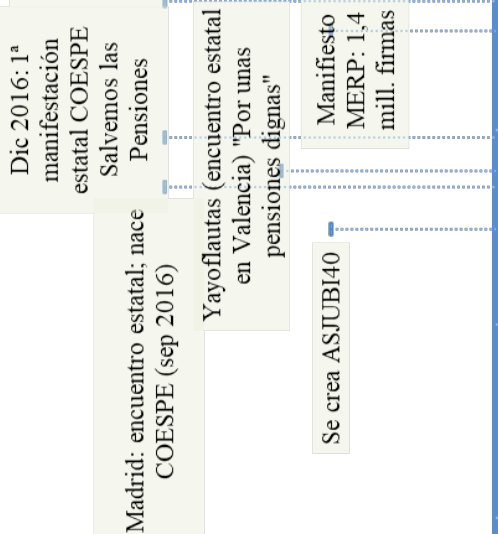

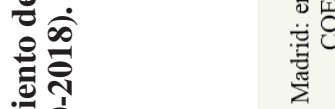
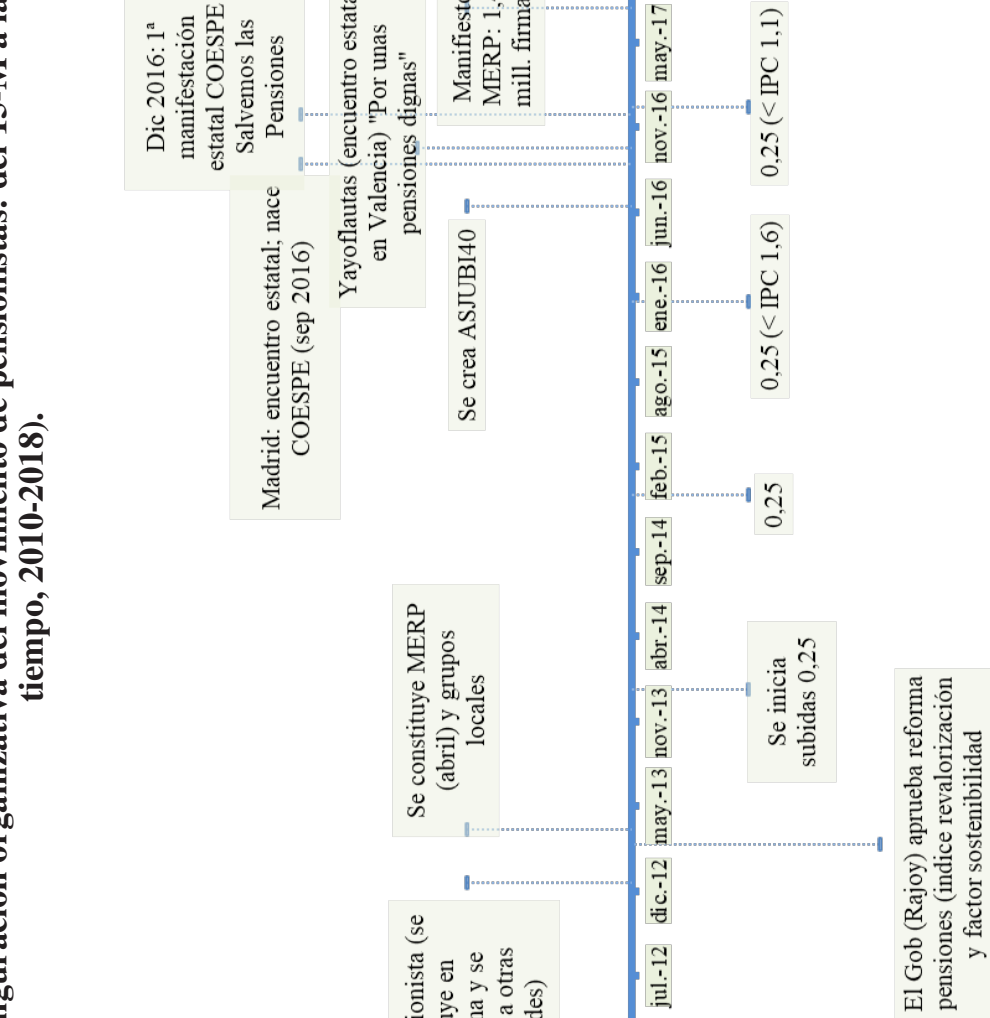

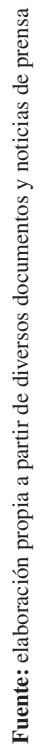


Junto a su clara opción por la protesta como forma de presión política, la aprobación de una "tabla reivindicativa" o listado de demandas resultó un elemento clave en su definición organizativa ${ }^{25}$. La adopción de una posición común en forma de esta tabla, no solo establece un horizonte de objetivos que orienta la continuidad de la movilización, sino que, al mismo tiempo, delimitó los criterios de pertenencia y de confluencia con otros colectivos: "el apoyo a la tabla al margen de las siglas". Así, la tabla reivindicativa, los objetivos que contiene y el lenguaje (marcos) con los que se expresan, establece una hoja de ruta que permite a la COESPE, por un lado, ampliar las bases de potenciales apoyos ${ }^{26} \mathrm{y}$, por otro, diferenciar al movimiento de partidos políticos y organizaciones sindicales. El discurso que enmarca esta estrategia para definir y delimitar su identidad colectiva, aparece, con aprobación, en los relatos de los participantes en las movilizaciones. Por ejemplo, en esta entrevista surge al recordar como los portavoces en las primeras concentraciones se afanaban por distanciarse de las siglas:

"Un detalle muy importante es que pregonaron como que estas manifestaciones iban a ser totalmente ajenas a la acción de los sindicatos, ni de partidos políticos. No se admitían. Otra cosa es que viniesen a título personal los participantes o los miembros de esas organizaciones. Pero que no se toleraría ninguna enseña ni bandera que los identificase" (BI_H88_3)

El "anonimato" de los mensajes convocando el 15 de enero, puede interpretarse igualmente como expresión de esa estrategia dirigida a evitar la identificación del movimiento con siglas partidistas y, consecuentemente, la reducción de su potencial de movilización. Así se deriva de esta conversación con un entrevistado, muy activo a nivel local, cuando relata la concentración del 15 de enero:

E: ¿A la manifestación (...) que decidisteis ir por primera vez, ¿Quiénes eran los convocantes de esa...?

P: Nadie.

E: ¿Nadie?

P: Nadie. No hubo convocatoria.

E: Ajá, por eso decías al principio lo de anónimo [el mensaje de wasap].

P: Bueno, el anonimato, el anonimato no existe. Existe, pero hay alguien detrás. Lo que sí es cierto es que después del 15 de enero nos dijimos algunos: "oye, si no sabemos quién ha hecho esto,

25 "En las reuniones iniciales de la Coordinadora [COESPE] se consiguió dar un gran paso al concretarse nuestras demandas y reivindicaciones en un manifiesto que así las recoge" (véase entrevista a Victoria Portas: http://www.rebelion.org/noticia.php?id=234586). La tabla puede consultarse en le perfil de Facebook de COESPE ( https://www.facebook.com/COESPE/photos /a.216682162112802/400871763693840/

${ }^{26}$ Podría formar parte de la coordinadora cualquier ciudadano/a, colectivo u organización que asuma la tabla reivindicativa, siempre que, al margen de procedencias, trayectorias y vinculaciones personales, la presencia y participación en el seno de la coordinadora sea a título particular, como ciudadano y ciudadana (http://pensionistasdeasturias.info/normas-de-funcionamiento-de-la-coordinadora-estatal). 
ya ha tenido tiempo de salir. Ya que no salga (...), que no se lo adjudique nadie [BI_H66_1]

Y el mismo entrevistado señala cómo se reaccionó, ese día y, a partir de ese momento, cuando un grupo acudió portando banderas de su partido:

El primer día, el 15 de enero, el grupo con el que yo fui al centro del pueblo, íbamos con carteles manuscritos, pues un poco hablando del gobierno de Rajoy, de los robos, de las pensiones bajas, (...) Los diez o veinte que fuimos [de nuestro barrio] (...) nos llevamos la sorpresa de que, además, no había, como pensábamos, otros veinte o cuarenta del resto de [nombre del municipio], sino que se llenó la plaza. Claro, se llenó la plaza y nadie sabía a quién dirigirse ni que decir ni nada. Nosotros levantamos los carteles y aparecieron, no voy a dar nombres, con carteles impresos en color de un partido político local. Y fue algo instintivo, apareció un concejal de ese partido, se arrimó por ahí y le dije: "oye, fulanito", no voy a dar el nombre tampoco: "creo que los partidos no estáis en campaña. Esta movida es nuestra". Tardó cinco minutos en hacer que desaparecieran las siglas de aquellos carteles impresos a todo color (...). El lunes siguiente aparecieron tímidamente por ahí otros carteles, alguien que se había despistado y (...) la propia gente de la plaza se les echó encima y les dijo no queremos ni partidos ni sindicatos con siglas en esta movida... [BI_H66_1]

El relato es similar al mostrado al inicio de este apartado, por un entrevistado de otra localidad en lo que parece un proceso que tuvo lugar de manera recurrente en distintos lugares, ese 15 enero y las semanas siguientes. La idea de mantener la movilización como una iniciativa ciudadana, de los pensionistas, se difunde por tanto desde el primer momento, y resultó asumida y defendida por los participantes que se van incorporando a las protestas.

En definitiva, junto con la descentralización y la autonomía local, el apartidismo y la transversalidad como elementos de delimitación de la pertenencia resultan claves en la definición de la identidad colectiva del movimiento. Las decisiones organizativas en las fases de gestación del movimiento serán determinantes en los momentos posteriores de movilización, en la medida en que favorecieron una identidad propia aglutinante de diversas sensibilidades, al tiempo que se diferenciaba de organizaciones sindicales y partidos políticos. Estos elementos identitarios ayudan posteriormente a resistir las dinámicas de instrumentalización por parte de estas organizaciones, consiguiendo una voz propia, y configurar una imagen o identidad colectiva positiva para amplios sectores, independientemente de sus adscripciones políticas. 


\section{EL PROCESO DE IDENTIFICACIÓN COMO APRENDIZAJE DURANTE LA PARTICIPACIÓN EN LA PROTESTA}

Las entrevistas nos permiten conectar los esfuerzos organizativos realizados por los promotores de las movilizaciones con los procesos de aprendizaje e identificación de los participantes durante la experiencia de las movilizaciones. En la muestra de personas con las que hemos conversado, la visión positiva del movimiento es generalizada. Esto entra dentro de lo esperable: lo normal de alguien que participa en una protesta es que tenga una visión positiva de sus promotores. Dado el grado de desconfianza hacia los sindicatos entre la ciudadanía (González et al. 2018), tampoco resulta sorprendente la visión negativa que muestran también de manera generalizada los participantes. Aunque si es destacable que pese a los esfuerzos movilizadores de los sindicatos (véase Figura 1) esa percepción negativa no se corrija y, en muchos casos, se vea reforzada. Solo en dos casos no se comparte la visión positiva mayoritaria. Se trata de participantes esporádicos (y con poca experiencia previa).

Al margen de estos dos casos, el análisis de las entrevistas conduce a establecer una serie de componentes discursivos principales (códigos) relativos al proceso de identificación. La presentación de estos resultados se apoya en dos gráficos. El gráfico 1 representa el número de entrevistas en las que hemos identificado cada uno de estos componentes discursivos, diferenciando los casos en los que se utiliza la primera persona del plural (nosotros). La figura 3 muestra el mapa de correlaciones de las coincidencias de estos componentes en las distintas entrevistas (no necesariamente en una misma cita), así como su asociación a tres rasgos de los entrevistados: la condición de afectado (tal como la hemos definido anteriormente), el nivel de experiencia previa y el grado de implicación en las movilizaciones.

En las narraciones, la desconfianza hacia los sindicatos se sitúa en momentos previos a las movilizaciones. Son frecuentes las referencias a experiencias negativas con los sindicatos durante su etapa laboral activa. Muchos señalan haber pertenecido a algún sindicato y haberlo abandonado al sentirse traicionados. En algunas ocasiones, la desconfianza parece verse reforzada como consecuencia de la movilización. Aquí, las valoraciones negativas van acompañadas de reproches y acusaciones de oportunismo (como las que se presentan a continuación). El relato recurrente de un proceso de distanciamiento durante la etapa laboral activa explicaría la dificultad de los sindicatos para movilizar a los jubilados más allá de sus militantes. En algunos casos, entre los que cuenta con más experiencia previa de participación en protestas, el discurso negativo se matiza, diferenciado a las organizaciones de los sindicalistas: "Tengo poca confianza [en los sindicatos]. Y es una pena porque conozco a sindicalistas auténticos, gente muy currela, pero los sindicatos han perdido el tren y no encuentran el sitio" [BI_M63_3]. 


\section{Gráfico 1. Frecuencia de componentes discursivos entre los entrevistados}

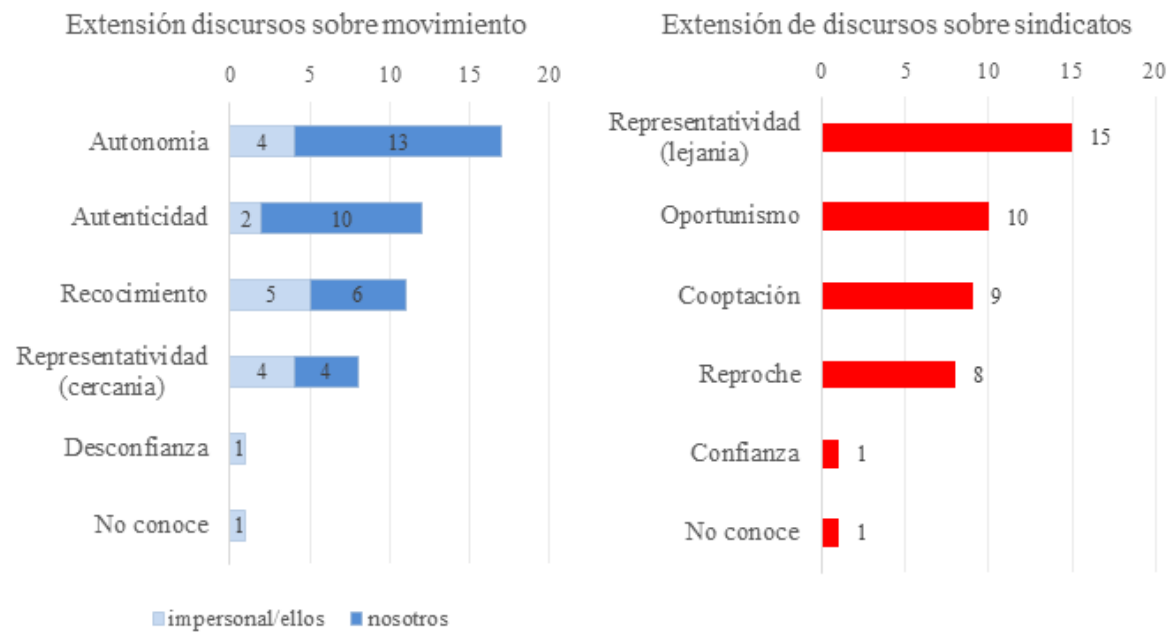

Fuente: elaboración propia a partir de 24 entrevistas a participantes del proyecto PROTEiCA

De manera más específica, se han identificado cuatro tipos componentes discursivos sobre los sindicatos sobre los que se fundamenta la desconfianza (véase gráfico 1). El más frecuente (registrado en 15 entrevistas) presenta una imagen de los sindicatos como ajenos a los problemas de los pensionistas, lejos de representar sus intereses. También, con bastante frecuencia, se les atribuye ser parte o estar del lado de los poderosos ("son parte de los de arriba") y estar cooptados ("dependen del gobierno", "son unos "traidores").

E: ¿Y en los sindicatos?

P: "Puf, personalmente desconfío totalmente, precisamente por lo que hablamos al principio de que han estado 5 o 6 años sin moverse y ahora empiezan ellos a querer ser la cabeza. Entonces no confío nada y más desde entonces en el comité de empresa cuando nos vendieron, desde entonces no confío nada en los sindicatos, desde que empezaron a estar subvencionados por el estado, dejaron de ser sindicatos. Los sindicatos tienen que ser libres e independientes. [MA_H68_1]

Como puede verse también en el fragmento anterior, otro componente discursivo gira en torno al reproche: "no han hecho nada, teniendo poder para hacerlo":

¿Cuándo se han movilizado los sindicatos con el 0,25? ¿Cuánto tiempo hace que no hacen una huelga general como se tenía que haber hecho ya? (...) A mí me llaman sindicalista y me enfadaría, me cabrearía, pero mucho. Es como si me dijeran una palabrota" [MA_H69_1] 
En este otro caso el reproche aparece de manera espontánea cuando se pregunta sobre la presencia del tema de las pensiones en las conversaciones cotidianas en un momento anterior a las movilizaciones. Aquí, el reproche de la inacción sindical se conecta con el sentimiento de agencia colectiva, que hemos señalado como componente básico del concepto de identidad colectiva. Como se deriva del relato, este sentimiento es producto de la experiencia de la movilización colectiva y no previo a la misma:

E: ¿Y cuando tenían estas conversaciones hablaban de qué podía hacerse con el tema?

P: Pues la verdad es que ese comentario se hacía poco. Lo único que sí sé, que siempre se manifestaba es que había que hacer algo, pero en ese momento no pensábamos en quién porque como da la casualidad que los sindicatos no se hacían ver, no se les oía. Porque a ver, aunque estuvimos 5 años con el 0,25 y aquí no se movía nadie y hasta que no empezamos los pensionistas directamente a salir a la calle, no se ha movido nadie. Y ahora, se quieren abanderar el motivo para ellos, los sindicatos, se han querido meter y van por otro sitio porque no les hacemos caso. [MA_H68_1]

La visión negativa de los sindicatos contrasta con la identificación positiva del movimiento que, en ocasiones, concurren, de manera natural, en un mismo relato (fragmento o cita). En todas las entrevistas, salvo en dos casos, existe cierto conocimiento sobre quién "organiza" las movilizaciones. Un número amplio muestra sentimientos de pertenencia al movimiento. Cuando en las entrevistas se habla del movimiento resulta frecuente la utilización, de manera espontánea, de la primera persona del plural para hablar del movimiento: en 15 entrevistas se utiliza al menos una vez. Esto ocurre en las entrevistas a personas más activas, y en menor medida, entre las menos implicadas. En la mayoría de los casos, el referente organizativo de ese "nosotros" es el grupo local, la plataforma en la que son activos o que les mantiene informados. El sentimiento de identificación mutua se conecta, por tanto, a la experiencia de la interacción personal en el ámbito más próximo y permite considerar su amplia extensión con la naturaleza descentralizada del movimiento. 


\section{Figura 3. Mapa de relaciones entre componentes discursivos sobre el movimiento y los sindicatos $(*)$.}

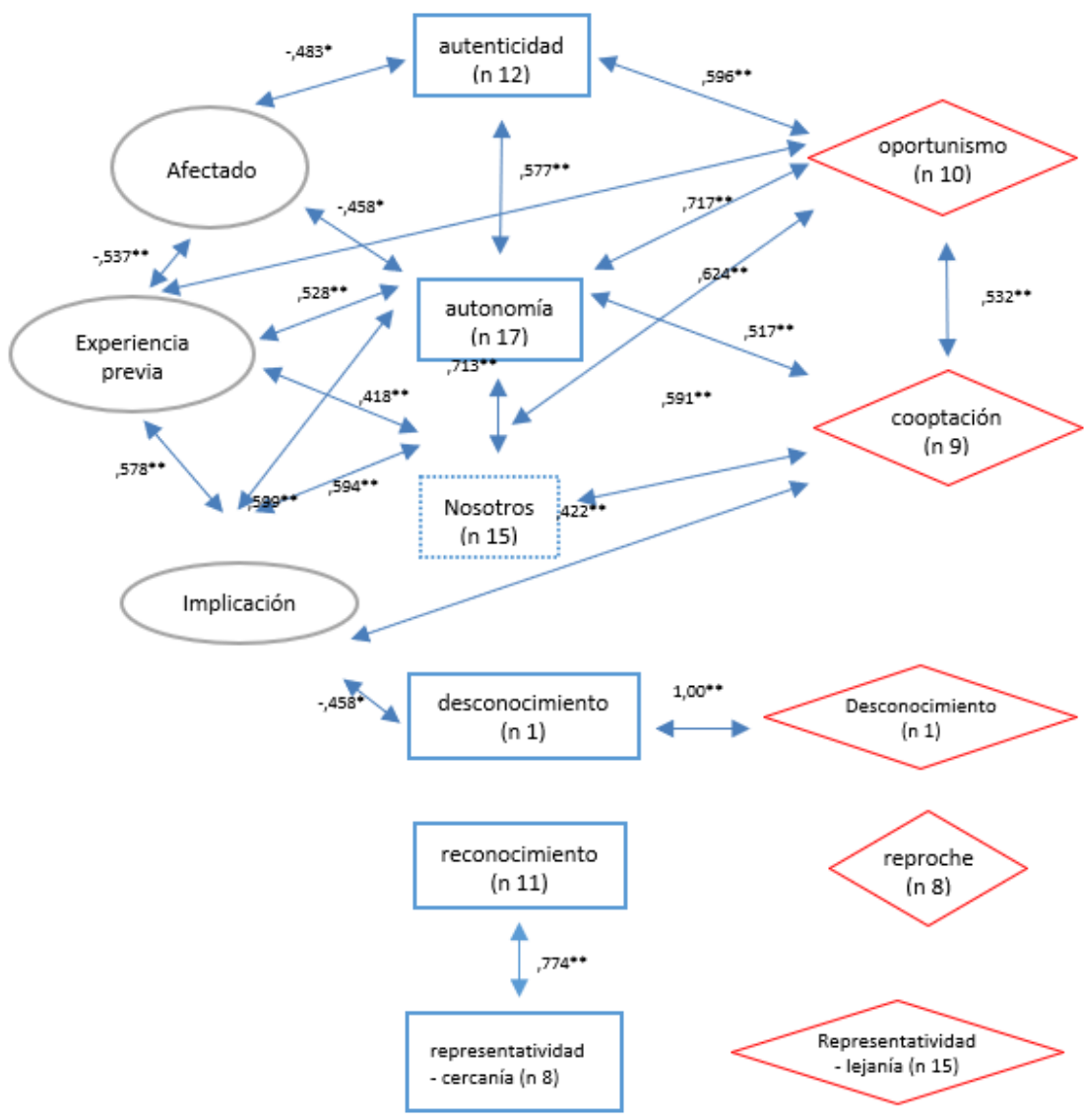

*El gráfico representa las conexiones (codificación en una misma entrevista) entre los componentes discursos (códigos) sobre el movimiento (rectángulos) y los sindicatos (rombos), así como con tres atributos de los participantes (óvalos). Los números dentro de las formas indican el número de entrevistas en las que se ha codificado ese componente.

Fuente: Elaboración propia, a partir de un análisis de correlaciones significativas $(n=23)$.

¿Y qué dicen sobre el movimiento? Las referencias más frecuentes son a la autonomía respecto a los partidos políticos y sindicatos, y al origen espontáneo y genuinamente ciudadano del movimiento (codificado con la etiqueta de autenticidad). Como ilustran las dos siguientes citas, ambos componentes, la autonomía y la autenticidad, suelen coincidir en las entrevistas (véase figura 3) y aparecen frecuentemente conectados en un mismo relato (co-ocurren en 13 citas): 
E: ¿Qué opinas tú de que los pensionistas se estén movilizando?

P: En general, me parece una gran alegría, porque vemos a todo el mundo que está algo desmotivado, a nivel de movilizaciones, cada vez más. Entonces, esta movilización, como ha salido además de forma un poco espontánea y sin ser dirigida ni por partidos, ni agrupaciones, ni nada, me parece muy bien [BI_H73_3]

Yo estas plataformas las veo bastante bien, bastante bien porque no están metidas en nada de política [BI_H73_1]

Estos componentes discursivos son más frecuentes entre los más activos (véase correlaciones en la figura 3), quizás los más conscientes de que la estrategia del movimiento, su éxito, pasa por subrayar la distancia respecto a partidos y sindicatos, y difundir el relato de su origen como iniciativa ciudadana espontánea. El esfuerzo por mantener la autonomía al tiempo que la apertura hacia todas las sensibilidades también se refleja en los discursos de los que ejercen el liderazgo en esos grupos locales que se formaron a partir del 15 de enero:

“(...) Cuando cojo el megáfono e invito a todos: "Esto está abierto el que quiera exponer sus ideas", eso sí, les digo: “ojo, aquí el que coja el megáfono habla de pensiones. Lo que quiera, pero de pensiones. Aquí no se menciona ni a partidos políticos, ni a sindicatos. Cada uno podemos ser de donde queramos, pero aquí, no se menciona”. Y ese es el éxito, que conste. [BI_H68_1]

"Hoy en día la coordinadora de [nombre del municipio] está formada por, yo creo, sensibilidades de todo tipo, política, sindical, incluso no sé, de otro tipo, está formada por treinta y tantas personas, voluntarios voluntarias todos y en ningún momento hemos sacado a relucir las siglas políticas ni sindicales. Es decir, el objetivo era qué podemos hacer porque las pensiones vuelvan al estatus que tenían anteriormente. Y qué podemos hacer, porque las reformas laborales, porque el trabajo, qué podemos hacer para que esto se enderece un poco" [BI_H66_1]

En los discursos de los más implicados se emplea con frecuencia el término apartidismo lo que sugiere cierto nivel de sofisticación política. El uso de este término (en lugar del de apoliticismo) se puede conectar con los marcos discursivos promovidos por el 15-M en los que se articula la exitosa critica a los partidos políticos y al sistema de representación (Romanos y Sábada 2015). La adhesión al apartidismo entre los pensionistas también se refleja en menciones al eslogan "gobierne quien gobierne" para reforzar la idea de que el movimiento no es un instrumento de los partidos.

"En la Plataforma, además no se puede ser, es totalmente apartidista que no política porque [...] De hecho, no nos reunimos en ninguna sede de partido ni nada, nos vamos a bares, hacemos las asambleas abiertas en plazas" [SE_M64_3] 
En algunas ocasiones, la autonomía se problematiza, mencionado la amenaza de la instrumentalización o la necesidad de resistir esas estrategias de instrumentalización por parte de organizaciones partidistas o sindicatos.

"Porque, en cierta manera, en un principio, se habló de que esto iba a ser una asociación un poco independiente al tema político. Y últimamente le están metiendo mano un poco ahí UGT, CCOO, y están tratando de quererlo torcer" [SE_H60_2]

Como se observa en la figura 3, los discursos basados en la autonomía-autenticidad están asociados a los discursos que otorgan atributos contrarios (cooptación, oportunismo) a los sindicatos. En su conjunto, esos componentes se combinan en un paquete discursivo que alinea a los participantes con el planteamiento organizativo presente en la fundación de la COESPE. Este paquete discursivo está presente entre los participantes más activos y los que se sienten integrantes en primera persona del movimiento. La congruencia entre los planteamientos organizativos y los discursos de los participantes indican el éxito del trabajo de creación de la identidad colectiva por parte de los promotores de la protesta.

En las entrevistas se pueden identificar dos componentes discursivos adicionales sobre el movimiento que hacen referencia a la cercanía (identificado en ocho entrevistas) y al reconocimiento de su labor (once entrevistas). De manera menos nítida, estos dos componentes constituyen un segundo bloque discursivo (co-ocurren en 6 citas, véase también la Figura 3). Si en el bloque anterior predominaba el uso del "nosotros" y el referente habitual eran las organizaciones (y los sindicatos como contraste), aquí se utiliza con más frecuencia el "ellos" para referirse a las personas más implicadas en los colectivos locales. Por un lado, las referencias a su cercanía y al conocimiento personal se articula como un atributo de representatividad del movimiento. Se trataría de una representatividad tanto descriptiva ("son de los nuestros", "nos representan", "los conocemos") como sustantiva ("me informan", "defienden mis intereses"). Por otro lado, en referencia a la actuación del colectivo, surge un discurso de gratitud y reconocimiento a su labor como trabajo desinteresado "son luchadores", "son los únicos que se han movido", "trabajan por mí".

Yo con la gente que es la que lleva el cotarro, les admiro [BI_H68_1]

"Yo creo que estas funcionan muy bien, ¿eh? Yo creo que no son muy... Hay algunos que se les nota, porque ya conoces tú a la gente del pueblo y de qué partido son más o menos, ¿no?, y se les nota que, aunque no quieren decir de qué partido, o que es el partido el que les lleva a esto, pero se nota. Bueno, "se nota" yo, que conozco a gente, ¿no? Y... pero... yo creo que funcionan muy bien, ¿eh? Por lo menos las plataformas estas no son peseteras, ahí están. No se ha parado ni un solo lunes... [BI_M65_2]

Estos discursos de reconocimiento y cercanía no dejan de ser expresiones de identificación o en su defecto de simpatía. Se trataría de una segunda línea de identificación, más cercana a la visión externa de la identidad, al reconoci- 
miento del colectivo como actor autónomo del que nos habla Melucci (1995). En cualquier caso, en el caso de los entrevistados pueden considerarse expresiones de compromiso y solidaridad, que como refleja la siguiente cita de un asistente frecuente, motivan la continuidad de la participación:

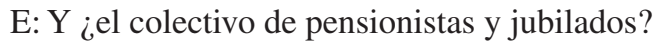

P: Pues hombre, yo te digo que esta gente, los que están aquí en [localidad], yo veo buena gente y les veo que están, digo, luchando. Creo que están luchando y con ganas. Y hay que apoyarles en todo lo que se pueda (...) ¿Qué hay que ir a un sitio? Pues se va. ¿Que hay que ir a otro? Pues se va. Hay que apoyarles.

E: ¿Usted se identifica con la plataforma?

P: Yo, hombre, ya he dicho antes (...) son gente que están poniendo de su tiempo al servicio de mucha gente. Entonces, primero al servicio mío, también, pues claro (...) Y entonces la información me llega a mí por ellos. (...) Entonces, mientras que estén ellos, de momento, me identifico con ellos [BI_H69_1]

El reconocimiento y la cercanía (representatividad) conectaría o se vería facilitada por esa percepción del movimiento como auténtico (como una iniciativa ciudadana espontánea) y, que cabe pensar, propicia los sentimientos de confianza y lealtad entre los participantes menos implicados y sobre los que se construye igualmente la identidad colectiva.

\section{CONCLUSIONES}

Este trabajo analiza empíricamente el proceso de configuración de la identidad colectiva de los pensionistas desde una doble perspectiva: como resultado de estrategias organizativas de movilización y como resultado de aprendizajes individuales durante la experiencia de la protesta. Desde la perspectiva organizativa, las bases identitarias del movimiento se vinculan a los esfuerzos estratégicos de una serie de actores colectivos, como los Yayoflautas, que previamente, durante la Gran Recesión, iniciaron la movilización en torno a la identidad de las personas mayores (Schwarz 2019). En 2013, diversos emprendedores de la protesta inician un proceso de organización para contestar las medidas regresivas adoptadas como parte de las políticas de austeridad. Estas iniciativas, como Marea Pensionista, adoptan elementos organizativos y discursivos característicos de las movilizaciones del 15-M como el asamblearismo y la descentralización, así como la horizontalidad y el apartidismo. Estos elementos favorecen, por un lado, el proceso de ampliación de los apoyos potenciales y, por otro, la diferenciación del movimiento frente a partidos políticos y organizaciones sindicales (establecen los límites de su identidad colectiva).

Con variaciones en función de sus perfiles, trayectorias y grado de implicación, el análisis de las entrevistas a participantes indica que el sentimiento de pertenencia y el sentido de agencia colectiva, como elementos básicos de 
la identidad colectiva, se configuran durante la experiencia de la protesta. Esta identificación colectiva gira en torno a dos elementos centrales, que se articulan como paquetes discursivos en el análisis de las entrevistas. Por un lado, la visión del movimiento como autónomo (desvinculado de partidos y sindicatos) y auténtico (que surge de manera espontánea como iniciativa ciudadana). La autonomía-autenticidad que caracteriza la percepción del movimiento se define en oposición a atributos contrarios que se atribuyen a los sindicatos (cooptación, oportunismo). De esta manera, no solo se logra ampliar el potencial de movilización a las distintas afinidades ideológicas (su transversalidad), sino que permite su reconocimiento como actor diferenciado y con capacidad de acción autónoma. Este discursivo se articula de manera más clara entre los participantes más implicados y que se sienten integrantes en primera persona del movimiento. La congruencia entre los planteamientos organizativos y estos discursos evidencian el éxito del trabajo de construcción de la identidad colectiva por parte de los promotores de la protesta.

Por otro lado, en el análisis de las entrevistas aparece un segundo paquete discursivo vinculado a la identidad colectiva en torno a las ideas de cercanía (representatividad) y reconocimiento (de la labor de los activistas). Se trata de relatos que tienen como referente a los activistas locales y pueden considerarse igualmente indicadores de identificación, o en su defecto de simpatía. Se trata de expresiones que indican la percepción del colectivo como actor autónomo. El reconocimiento y la cercanía (representatividad) conectan con la percepción del movimiento como auténtico (como una iniciativa ciudadana espontánea) y propicia sentimientos de confianza y lealtad entre los participantes menos implicados. La naturaleza descentralizada de la base organizativa del movimiento, en tanto que facilita la cercanía vuelve a resultar clave para comprender el origen y la continuidad de la movilización de los pensionistas.

Desde una perspectiva analítica, el trabajo ilustra la conveniencia de considerar la identidad colectiva desde esta doble perspectiva, como estrategia organizativa y como aprendizaje que tiene lugar durante el proceso de movilización. En este sentido, junto a las aportaciones empíricas sobre el exitoso proceso de movilización de los pensionistas, el trabajo permite, por un lado, ubicar ese proceso en una trayectoria temporal más amplia de contestación popular y, en particular, vincularlo a los legados del ciclo de movilización que surge con la crisis a la estela del 15-M. Por otro lado, también permite destacar esos procesos de contestación como espacios de aprendizaje en los que se modelan las actitudes, valores y demás elementos de la cultura de protesta y que marca su evolución en el tiempo.

La naturaleza novedosa del movimiento de pensionistas en España, la creación ex novo de una identidad colectiva basada, por primera vez, en este grupo de edad, nos ofrece un contexto idóneo para explorar ese proceso de aprendizaje. No obstante, a pesar de que las entrevistas estimulan la dimensión temporal en el relato, para captar la dinámica del proceso de configuración de la identidad colectiva del movimiento resultaría idóneo su seguimiento en el tiempo (por ejemplo, volviendo a preguntar a los participantes), y registrar así cambios en 
sus percepciones más allá del primer año de intensa movilización en el que se inserta nuestro trabajo. Un reto para siguientes investigaciones consiste en abordar cómo se moldea esa identidad colectiva en un contexto de desgaste de la movilización, marcado por distintos eventos, como la pandemia o el relativamente limitado impacto del movimiento en la orientación de la política de pensiones.

En cualquier caso, este trabajo constata la importancia de la actividad colectiva de los mayores en España y la necesidad de investigarla. La progresiva incorporación de generaciones con niveles educativos y socializaciones políticas en democracia hacen esperar un mayor protagonismo si cabe en la calle. La voz propia de los mayores que representa el movimiento de pensionistas en 2018, seguirá activa, en este y otros temas, en el futuro, y reclama mayor atención desde diversos ámbitos de estudio como el de los movimientos sociales y el comportamiento político.

\section{BIBLIOGRAFÍA}

ADELL, R. y OLAYO, A. (2014): "De la dignidad al poder de la ciudadanía. Balance de la protesta 2014", Anuari del Conflicte Social, 4, pp. 735-764.

ALEJOS, L. (2018): "El movimiento de pensionistas Fenómeno singular de largo alcance”, Lan Harremanak. Revista de Relaciones Laborales, 40, pp. 31-48.

ALEJOS, L. (2019): Pensionistas, un año tomándole el pulso al gobierno de turno. Eldiaronorte.es. Recuperado el 6 de diciembre de 2019, disponible en: https://www.eldiario.es/norte/vientodelnorte/Pensionistas-tomandole-pulso-gobierno-turno 6 861323868.html

AZUMENDI, E. (2019): El muro de los pensionistas vascos se agrieta. Eldiaronorte.es. Recuperado el 10 de diciembre de 2019, disponible en:https://www.eldiario.es/norte/ Primeras-grietas-muro-pensionistas 0 970803782.html

CIS (2018): Barómetro de marzo de 2018. Estudio 3207. Disponible en: http://www.cis. es/cis/opencm/ES/1 encuestas/estudios/ver.jsp?estudio $=14387$

FINE, G. A. (2018): "Now and Again: Eventful Experience as a Resource in Senior Activism", Social Movement Studies, 19, pp. 576-591.

FLESHER FOMINAYA, C. (2010): "Collective Identity in Social Movements: Central Concepts and Debates", Sociology Compass, 4(6), pp. 393-404.

FLESHER FOMINAYA, C. (2015): “Debunking Spontaneity: Spain's 15-M/Indignados as Autonomous Movement", Social Movement Studies, 14(2), 142-163.

GAMSON, W. (1990): The Strategy of Social Protest, Belmont, Wadsworth.

GONZÁLEZ, B. RODRÍGUEZ, V. y CUETO, B. (2018): “Aloración Pública y Legitimidad Social de Los Sindicatos En La Crisis Económica” en Anuario IET de Trabajo y Relaciones Laborales 5:195.

HEBERLE, R. (1951): Social Movements an Introduction to Political Sociology, New York,Appleton-Century-Crofts.

HUNT, S. y BENFORD, R. (2004): "Collective Identity, Solidarity, and Commitment" en The Blackwell Companion to Social Movements, Reino Unido, Wiley-Blackwell, pp. 433-57.

JASPER, J. (1998): "The Emotions of Protest: Affective and Reactive Emotions in and around Social Movements", Sociological Forum 13(3), pp. 397-424. 
JIMÉNEZ, M. y CALLE, A. (2007): "The Global Justice Movements in Spain". En Global Justice Movement. Cross-national and Transnational Perspectives, Boulder, Paradigm Publishers, pp. 79-102.

JIMÉNEZ, M, ÁLVAREZ, R. y BETANCOR, G. (2020): "Construyendo una voz propia: las movilizaciones de pensionistas en España en 2018", en VVAA (eds) Acción colectiva, movilización y resistencias en el siglo XXI, FES-Betiko, pp. 109-124.

MCADAM, D. (1982): Political Process and the Development of Black Insurgency, 1930-1970, Chicago , University of Chicago Press.

MELUCCI, A. (1989). Nomads of the Present : Social Movements and Individual Needs in Contemporary Society. Temple University Press.

MELUCCI, A. (1995): "The Process of Collective Identity", en Social Movements and Culture, Minnesota, University of Minnesota Press, pp. 41-63

OLSON, M. (1965): The Logic of Collective Action : Public Goods and the Theory of Groups, Cambridge (Massachusetts), Harvard University Press.

PATTON, M. Q. (1990): Qualitative evaluation and research methods (2nd ed.), Newbury Park, Calif, Sage Publications.

POLLETTA, F. y JASPER, J. (2001): "Collective Identity and Social Movements." Annual Review of Sociology 27(1), pp. 283-305.

PORTOS, M. (2016): "Movilización social en tiempos de Recesión: un análisis de eventos de protesta en España, 2007-2015”, Revista Espanola de Ciencia Politica 1(41), pp. 159-78.

ROMANOS, I. y SÁDABA, I. (2015): "La evolución de los marcos (tecno) discursivos del movimiento 15M y sus consecuencias", Empiria. Revista de Metodología de Ciencias Sociales, 32, pp. 15-26.

SCHWARZ, C. (2019): "Collective Memory and Intergenerational Transmission in Social Movements: The "Grandparents' Movement" Iaioflautas, the Indignados Protests, and the Spanish Transition", Memory Studies.

SIMON, B., Y KLANDERMANS, B. (2001): "Politicized collective identity: A social psychological analysis", American Psychologist, 56(4), 319-331.

SNOW, D. (2001): "Collective Identity and Expressive Forms" en International Encyclopedia of the Social \& Behavioral Sciences, Elsevier, pp. 2212-2219.

STRAUSS, A. L. y CORBIN J. M. (1990): Basics of qualitative research : grounded theory procedures and techniques, Newbury Park, Calif, Sage Publications.

TAVORY, I. y ELIASOPH, N. (2013): "Coordinating Futures: Toward a Theory of Anticipation", American Journal of Sociology, 118(4), 908-42.

UPD -Barómetro Mayores. (2018): Solidaridad familiar. Ayudas económicas de los mayores a sus familiares. Disponible en https://www.mayoresudp.org/informe-delmayor-udp/

VALLES, M. S. (2002): Entrevistas cualitativas, Madrid, CIS. 